\title{
POSSÍVEIS IMPLICAÇÕES DA PRODUÇÃO DIAGNÓSTICA NAS PRÁTICÁS DE EDUCAÇÃO ESPECIAL
}

http://dx.doi.org/10.5902/2318133841347

\author{
Gabriela Orengo Pedrozo ${ }^{1}$ \\ Eliana da Costa Pereira de Menezes²
}

\begin{abstract}
Resumo
Neste texto apresenta-se uma reflexão sobre a gestão das práticas de educação especial exercidas na escola regular, considerando o contexto da educação inclusiva. Objetivou-se analisar possíveis implicações do diagnóstico nas práticas de educação especial a partir dos discursos de medicalização. A materialidade analítica do estudo foi estruturada a partir de entrevista realizada com uma professora de educação especial, de uma escola particular da rede regular de ensino do município de Santa Maria/RS. Entende-se que os discursos da medicalização que têm se constituído como mecanismo de governamento na sociedade contemporânea, podem acabar produzindo na escola a individualização de problemas que são coletivos, adoecendo assim comportamentos cujas causas são muitas vezes sociais e não orgânicas.
\end{abstract}

Palavras-chave: práticas de educação especial; escola comum; medicalização; políticas inclusivas.

\section{POSSIBLE IMPLICATIONS OF DIAGNOSTIC PRODUCTION IN SPECIAL EDUCATION PRACTICES}

\section{Abstract}

This study presents a reflection on the management of special education practices in regular schools, considering the context of inclusive education. The objective was to analyze possible implications of the diagnosis on special education practices from the medicalization discourses. The analytical materiality of the study was structured based on an interview with a special education teacher, from a private school in Santa Maria / RS. It is understood that the speeches of medicalization that have been constituted as a governing mechanism in contemporary society, end up producing in the school the individualization of problems that are collective and thus sickening behaviors whose causes are often social and not organic.

Key-words: special education practices; common school; medicalization; inclusive policies.

\footnotetext{
${ }^{1}$ Emef Artur Bernardo Schmidt, Brasil. E-mail: gabpedropedrozo@gmail.com.
}

2 Universidade Federal de Santa Maria, Brasil. E-mail elianacpm@hotmail.com. 


\section{Introdução}

studos como o de Moysés (2001) indicam que é consideravelmente significativa a incidência de diagnósticos entre as crianças em idade escolar. Segundo a autora já na educação infantil, no decorrer das séries iniciais e também nas séries finais, o número de diagnósticos vem aumentando desde os anos 1990. Pode-se compreender que entre os fatores que têm provocado esse aumento nos encaminhamentos e buscas pelo diagnóstico, estão as mudanças de critérios para avaliação e captura de sinais que possam localizar os alunos como alunos que não se encaixam na normalidade instituída.

Tais critérios aparentam estar cada vez mais abrangentes, abarcando singularidades da vida cotidiana o que, em muitos casos, possa ser justificado pelos contextos e histórias de vida de cada um de nós. Assim, parece ser difícil qualquer um de nós não se encaixar em algum dos transtornos mentais apresentados ${ }^{3}$. Assim,

a medicalização dos desvios é possível por meio da flexibilização dos limites do que é considerado normal e do que não é. A era moderna da classificação diagnóstica em saúde mental se originou nos asilos, porém hoje os manuais diagnósticos não estão restritos a esses espaços. Suas categorias parecem englobar não somente uma pequena minoria da população, mas quase todos nós. Os diagnósticos psiquiátricos incluem uma variedade de condições que se situam, de acordo com Rose (2006), na fronteira da normalidade, tais como ansiedade, pânico, depressão leve a moderada, transtornos de personalidade, TDAH, transtornos de conduta e transtornos do espectro autista. (Brzozowski; Capelo, 2013, p. 2010)

Nesse contexto, prestou-se atenção ao público infantil, pois as dificuldades de aprendizagem, de socialização e os comportamentos indisciplinados das crianças têm sido vistos como patologias que justificam encaminhamentos precoces das crianças ao campo da Medicina em busca de diagnósticos que expliquem tais modos de ser e estar na escola. A produção de um diagnóstico poria essas crianças na condição de alunos para quem uma série de prescrições, na aliança entre ações da clínica - terapias e medicamentos - e práticas educacionais, especialmente as conduzidas pela educação especial, são visualizadas como capazes de controlar, reabilitar e, quando não for possível, normalizar, aproximar os alunos de gradientes aceitáveis de normalidade.

Medicaliza-se a criança por apresentar determinados comportamentos, mas não se investiga o contexto social que pode também estar produzindo tais comportamentos. Dentre esses contextos, localiza-se também a escola. Que relações são produzidas no contexto escolar? Como essas relações são conduzidas diante da indicação da percepção de um comportamento considerado não adequado? Que efeitos nas relações escolares são provocados pela efetivação de um diagnóstico e a consequente medicalização do aluno?

Segundo Moyses (2001) a medicalização pressupõe o processo vivido na atualidade em que transformamos em problemas individuais problemas que são coletivos. Assim, ao olharmos para alunos na escola, que por apresentarem singularidades em seus

\footnotetext{
${ }^{3}$ Ver, por exemplo, o Manual diagnóstico e estatístico de transtornos mentais - DSM 5, publicado em 2014. Regae: Rev. Gest. Aval. Educ. Santa Maria v. 9 n. 18 Pub. contínua 2020 p. $1-14$
} 
processos de aprendizagem, são responsabilizados individualmente e submetidos a encaminhamentos clínicos em busca da produção de diagnósticos, estamos estabelecendo com ele uma relação baseada nos princípios da medicalização.

\section{Elementos teórico-metodológicos}

Ao produzir o estudo buscamos salientar a importância de fomentarmos a discussão sobre como os sujeitos apoiados pela educação especial são produzidos no espaço escolar e como a escola produz formas de olhar para esses sujeitos que estão quase sempre amparados na necessidade de diagnosticar, e quando possível medicar, para poder atuar.

$\mathrm{Na}$ tentativa de fazer essa análise inspirou-se em Michel Foucault. Para este o sujeito é produto das relações de poder que, ao instituírem modos de ser mais verdadeiros, passam a produzir determinadas formas do sujeito se relacionar consigo mesmo. A partir da compreensão de que os discursos da área da saúde parecem ser os que são vistos como verdades absolutas nas escolas e na sociedade, entendemos que somos subjetivados. Assim, a atenção recai nos discursos sobre a medicalização dos alunos que são ou passam a ser apoiados pela educação especial, problematizando os possíveis efeitos nas suas relações escolares.

Pela perspectiva pós-estruturalista busca-se entendimentos que tragam diferentes formas de compreender o que está sendo feito nas escolas com naturalidade. Busca-se problematizar os efeitos que os diagnósticos podem causar na vida de alunos numa tentativa de rever também as verdades que nos constituem como professoras de educação especial, em um exercício de hipercrítica na perspectiva de Michel Foucault, a qual

está sempre pronta a se voltar contra si mesma para perguntar sobre as condições de possibilidade de sua existência, sobre as condições de sua própria racionalidade". A hipercrítica não imobiliza, não aquieta. Ela incomoda, desestabiliza, pois "se desloca sem descanso, sobre ela mesma e sobre nós (Veiga-Neto, 2005, p. 29)

Não se trata aqui de desejar produzir uma forma mais verdadeira de pensar as relações entre a escola e os processos de medicalização da infância e produção diagnóstica dos alunos, mas de construir uma análise provocativa sobre a tendência atual nas quais diagnósticos são produzidos e passam a constituir os alunos, produzindo-os como alunos com deficiências, transtornos, doenças, e assim medicalizam comportamentos sem atentar para os contextos individuais e as histórias pessoais dos alunos.

Procurando atender ao objetivo do estudo a materialidade analítica foi estruturada a partir de uma entrevista realizada com a professora de educação especial que atua em uma escola da rede particular de ensino do município de Santa Maria/RS. Essa professora, identificada pelas iniciais EE, possui formação em educação especial e exerce a função na escola a pouco menos de um ano. Seu contrato com a escola é de 28 horas semanais de trabalho e atende a 35 alunos identificados como alunos em processo de inclusão escolar. 
Para a realização da entrevista a professora foi convidada a assinar o termo de consentimento livre e esclarecido, no qual se explica a intencionalidade da pesquisa, apresenta-se benefícios e possíveis riscos de sua colaboração com o estudo. As questões que constituíram a entrevista procuraram conhecer a gestão da prática da educação especial na escola em que a professora atua diante da compreensão de aspectos como o número de alunos atendidos a existência de diagnósticos os encaminhamentos que são realizados o lugar que o diagnóstico ocupa na sua prática, entre outras.

Segundo Moysés (2001) há crianças cujas condições concretas de vida estão mais distantes dos benefícios produzidos pelo desenvolvimento científico e tecnológico atual do que outras crianças que viveram há décadas. $O$ que não significa que sejam menos capazes, mas que apresentam um desenvolvimento cognitivo conformado por suas necessidades e possibilidades concretas, pelo bloqueio de seu acesso aos bens culturais. Nesse sentido cabe refletir sobre as vivências e aprendizagens do indivíduo fora da escola. Como são estruturadas suas relações familiares e as interações que ele estabelece fora da escola? Seu universo familiar criou oportunidades que o possibilitasse conhecer e significar o mundo, internalizando tais significados? Como tais questões são consideradas pela escola no momento de encaminhamento dos alunos para avaliações clínicas? Para o professor de educação especial como a produção de diagnóstico tem sido determinante para as práticas que elas desenvolvem?

\section{A produção da infância anormal na escola}

Ao tentar analisar a produção diagnóstica e a gestão das práticas de educação especial numa escola comum, entendemos que é preciso compreender que o significado do termo gestão diz respeito a forma como as práticas da educação especial dentro da escola comum, a partir da perspectiva da inclusão escolar, estão organizadas, sob quais intencionalidades elas são desenvolvidas e que efeitos elas podem produzir na constituição dos alunos.

A partir das análises sobre a produção de sujeitos na lógica neoliberal (Lopes, 2009) compreende que o sujeito constitui-se na escola contemporânea como um ser que deve pertencer a um espaço social, deve produzir, colaborar e aprender a se auto-gerir nesse espaço, contribuindo para uma sociedade mais produtiva, constituída por indivíduos empreendedores de si. A produção de sujeitos dentro dessa lógica pode resultar na diminuição de formas de vida que são dependentes de políticas de assistência e aumento na produção de formas de vida que contribuam para as políticas de previdência social:

Entre as estratégias criadas para que a normalidade se estabeleça dentro de quadros nos quais surge a ameaça do perigo, é possível citar a criação de políticas de assistência e de políticas de inclusão social e educacional, entre outras. Ambas, ao fim e ao cabo, podem ser vistas como ações inclusivas que visam a trazer para a normalidade, partes da população ameaçadas pela miséria, pela doença, pela deficiência, pela falta da previdência, pela falta da escola, etc. (Lopes, 2009, p. 160) 
Entende-se que as políticas de inclusão escolar passam a localizar a escola como instituição central nesse processo de identificação daqueles alunos que podem vir a ocupar o lugar de 'sujeito da assistência', procurando desenvolver para ele práticas de prevenção e estimulação que o produzam como um 'sujeito da previdência'. Ocorre que essa busca, cada vez mais antecipada, dos possíveis riscos presentes nos modos de ser de alguns aluno,s tem resultado na produção de diagnósticos e classificações que os localizam no grupo dos anormais, especialmente quando as dificuldades nos processos de aprendizagem emergem.

Para Brzozowski e Capelo (2011) a maioria das solicitações de avaliação clínica produzidas na infância

são notados na escola e descobertos a partir do momento em que a criança desenvolve algum problema de aprendizagem. Como exemplo, podemos pensar na alfabetização: se uma criança não aprende a ler com determinada idade, ou então se tem dificuldade em prestar atenção na sala de aula, isso pode ser considerado um desvio, e a criança pode, atualmente, ser encaminhada a um profissional da saúde para averiguar seu quadro. Os desvios da infância, dessa forma, são aqueles relacionados com a quebra de normas e de regras impostas socialmente, como, por exemplo, a falta de atenção e a agitação em sala de aula. (p. 210)

Conforme Lockmann (2016) a escola e a educação passaram a ser produzidas como estratégia de governamento, sendo insistentemente convocadas por políticas, programas e discursos públicos para solucionar as mazelas sociais. Nesse processo as práticas escolares, ao serem aclamadas como solução para problemas sociais que não são produzidos no interior da escola, transcendem os limites das suas responsabilidades e servem-se dos saberes clínicos para a produção de soluções via medicalização da infância de problemas que não necessariamente têm uma origem clínica.

Segundo Brzozowski e Capelo (2013) essa influência dos saberes da saúde nas práticas escolares têm se configurado de forma mais significativa no último século, o que pode indicar a medicalização da infância também como um efeito das políticas neoliberais que ao produzirem um ideal de aluno para a sociedade da produção e do consumo, acabam produzindo também uma postura vigilante da escola com relação àqueles que talvez não consigam se enquadrar nesse ideal.

Acreditamos que as práticas vividas no ambiente escolar se constituem através da convivência de diferentes indivíduos em determinado espaço social, devendo proporcionar aos alunos percepções da vida em sociedade e desenvolvimento das habilidades culturais, sociais e também afetivas, lembrando sempre que todos os indivíduos nesse contexto são diferentes, possuem peculiaridades, experiências distintas de vida. Estas questões devem ser levadas em conta no momento em que a criança se insere no ambiente escolar e o planejamento da instituição deve adaptar-se às diferentes demandas da sociedade, para que o professor compreenda e adapte as atividades oferecidas para acontecer a aprendizagem e o desenvolvimento de seus alunos.

A gestão das práticas de uma instituição escolar é um desafio intenso para os todos os sujeitos envolvidos, ainda mais quando essa instituição passa a ser produzida como aquela que será responsável pela produção de sujeitos aptos a uma vida produtiva em 
sociedade. É na escola que se inicia a vida acadêmica, é lá que começam as primeiras experiências, e também é lá que começam as comparações, competições e expectativas da maioria das pessoas quanto ao futuro.

Até a conquista dessa vida em sociedade os alunos deverão percorrer um percurso ideal imaginário. Quando alguns alunos, em função de múltiplos motivos, demonstram dificuldade ou incapacidade para trilhar tal percurso dentro dos padrões de normalidade, inquietações e questionamentos passam a ser produzidos em busca de respostas que justifiquem tal inadequação às normas.

Nesse processo acabamos buscando formas de identificar e nomear a diferença, a partir de encaminhamentos, avaliações e diagnósticos que localizam tais alunos na condição de anormais. Um diagnóstico, ao ser produzido, justifica comportamentos e marcas da anormalidade.

Inicia-se a construção de uma visão sobre o aluno respaldada pela Medicina. Quando os laudos confirmam uma hipótese diagnóstica pode-se passar a compreender o aluno como incapacitado, doente, deficiente, que vai ocupar o lugar da falta, da correção e, às vezes, da exclusão na escola. Passa-se a perceber não o que o indivíduo já sabe, mas sim o que se acredita que ele não seja capaz de saber. Costuma-se percebê-los como incapazes de pertencer de forma eficaz aos grupos, pois não obedecem às regras impostas pela sociedade. Daí surge o poder do diagnóstico como produto das relações de poder que envolvem os indivíduos. As famílias passam a perceber as diferenças nunca percebidas antes da vida escolar e começam a procurar o motivo das supostas diferenças e desajustes recorrendo às avaliações e quando necessário às prescrições medicamentosas. A possibilidade de receita de um medicamento que leve as crianças a superar os desajustes apresentados são assumidas como promessas de retorno a uma vida dentro da normalidade: "Em outras palavras, o modelo médico traz consigo uma visão otimista para o desvio, com a promessa de um resultado praticamente imediato" (Brzozowski; Capelo, 2013, p. 213).

Ao analisarem o aumento da produção diagnóstica de crianças com Transtorno de Atenção e Hiperatividade - TDAH - Brzozowski e Capelo (2013) apontam que

mães de crianças com TDAH, apesar de não gostarem de dar um medicamento psicotrópico para o filho, o fazem, primeiramente, por ser uma recomendação médica, portanto, indiscutível. Em segundo lugar, existe uma pressão por parte da escola para que essa criança receba uma avaliação e um acompanhamento médico. Por fim, existe ainda uma preocupação da adequação de seus filhos na sociedade, para que eles possam ter as mesmas oportunidades que os demais. (p. 213)

Entende-se que a produção das anormalidades na escola torna-se evidente a partir da operação de um tipo de poder nas relações entre os sujeitos que Foucault (1999) chamou de poder disciplinar. A disciplina controla os indivíduos fixando tempos e espaços de aprendizagem. Por meio dela se regula e controla os alunos, operando pela vigilância externa, que passa a ser interna, comportamentos ajustados e desejáveis. É dócil um corpo que pode ser submetido, que pode ser utilizado, que pode ser transformado e 
aperfeiçoado: "Esses métodos que permitem o controle minucioso das operações do corpo, que realizam a sujeição constante de suas forças e thes impõem uma relação de docilidade-utilidade, são o que poderíamos chamar as disciplinas. (Foucault, 1999, p. 126).

Nesse contexto o aluno que não se sujeitar às ações do poder disciplinar poderá ser demarcado como aquele que precisa de avaliação e correção, constituindo-se alvo das técnicas de normalização, entre as quais destaca-se a medicalização. Assim,

pode-se dizer que o elemento que vai circular entre o disciplinar e o regulamentador, que vai se aplicar da mesma forma, ao corpo e à população, que permite a um só tempo controlar a ordem disciplinar do corpo e os acontecimentos aleatórios de uma multiplicidade biológica, esse elemento que circula entre um e outro é a "norma". A norma é o que pode tanto se aplicar a um corpo quanto a uma população que se quer regulamentar (Foucault, 1999, p. 302)

Pela operação de práticas de normalização do poder disciplinar pode-se produzir um sujeito adequado à norma que, por sua vez, na coletividade, constituirá uma sociedade de normalização. Nesta conjuntura medicalizar se constitui como uma prática que visa à normalização. A forma como a criança que não aprende na escola vem sendo percebida na sociedade talvez seja a grande causa dos laudos, diagnósticos e prescrições médicas, cada vez mais recorrentes.

Quando o "corpo anormal é institucionalizado e submetido a um aparato de poder/saber que fixa os indivíduos em determinados espaços" (Lockmann, 2016, p. 270), passa-se a produzir sobre ele práticas que buscam avaliar e identificar para poder gerenciar, corrigir e prevenir. Embora o fenômeno da medicalização seja visto como dever da Medicina, em outros campos do saber, incluindo a educação, busca-se incansavelmente solucionar os problemas pela prevenção e a busca incessante por remédios, técnicas, métodos de cura.

Podemos entender que quando se individualiza um problema coletivo você está medicalizando-o, transformando-o um problema coletivo num problema individual. Portanto, medicalização é uma expressão utilizada para falar de um processo discursivo que transforma questões não médicas, problemas da humanidade - políticos, sociais, econômicos, escolares - em problemas médicos. A origem está no campo da Medicina e a solução também está nesse campo. Porém, na atualidade deve-se perceber que tal termo não vem apenas da área médica, mas também da área da Fonoaudiologia, Psicologia, Pedagogia e da própria Educação Especial.

\section{A criança que não se ajusta à norma e a gestão das práticas da educação especial em uma escola comum}

A relação entre processos diagnósticos e a prática da educação especial na escola comum diante das políticas de inclusão escolar foi discutida a partir da entrevista realizada com uma professora de educação especial de uma escola particular. 
A análise do diagnóstico e dos processos de medicalização da infância se inscreve no campo das Ciências Sociais, pois entende-se que estamos transformando em biológicos problemas que são socialmente produzidos. Seria por isso que a produção de diagnósticos em busca de marcas que justifiquem singularidades de comportamentos tem comumente sido produzido a partir de uma necessidade criada pela escola (Moysés, 2001).

A influência produzida pelos saberes da área da Saúde sobre as práticas da educação especial foi determinante para a emergência da própria área. $\mathrm{Na}$ atualidade, em função da emergência das políticas de inclusão escolar, essa influência aparentemente estaria enfraquecida, uma vez que elas se anunciam como políticas que pretendem provocar práticas escolares que signifiquem os sujeitos com deficiência a partir de parâmetros mais sociais do que clínicos. No entanto, ao analisar os documentos legais produzidos no país desde a apresentação da Política nacional de educação especial na perspectiva da educação inclusiva (2008) é possível identificar a centralidade presente na produção diagnóstica dos alunos.

Fundamentada nos marcos legais e princípios pedagógicos da igualdade de condições de acesso à participação em um sistema educacional inclusivo, a Política nacional de educação especial na perspectiva da educação inclusiva (MEC, 2008) define a educação especial como modalidade de ensino transversal a todos os níveis, etapas e modalidades, que disponibiliza recursos e serviços e 0 atendimento educacional especializado, complementar ou suplementar, aos estudantes com deficiência, transtornos globais do desenvolvimento e altas habilidades e superdotação no ensino regular.

Segundo a resolução CNE/CEB n. 4/2010, os sistemas de ensino devem matricular os estudantes com deficiência, transtornos globais do desenvolvimento e altas habilidades e superdotação nas classes comuns do ensino regular e no atendimento educacional especializado, complementar ou suplementar à escolarização ofertado em sala de recursos multifuncionais ou em centros de $A E E$ da rede pública ou de instituições comunitárias, confessionais ou filantrópicas sem fins lucrativos.

Segundo tais documentos os estudantes público alvo da educação especial devem ser matriculados nas classes comuns, em uma das etapas, níveis ou modalidade da educação básica, sendo o AEE ofertado no turno oposto ao do ensino regular. A matrícula dos alunos nas turmas de AEE é condicionada pela inserção dos alunos no censo escolar, o que pressupõe a inserção dos mesmos em alguma das classificações diagnósticas que legitima sua condição de aluno público-alvo da Educação Especial.

Assim, ainda que determinados alunos não possuam diagnósticos oficializados por laudos médicos, para que seja possível sua inserção no formulário do censo escolar, é preciso que eles sejam classificados em alguma das condições diagnósticas que ali são apresentadas. Nesse contexto a melhor forma de desvincular a ação medicalizadora da atuação da Educação Especial na escola comum depende da ação do professor do atendimento educacional especializado no que diz respeito aos processos e estratégias de ensino voltadas aos alunos com deficiência no ambiente escolar, o que beneficiaria os alunos com diagnóstico e também aqueles que de alguma maneira não o possuem, mas que de certa forma também necessitam do atendimento educacional especializado. 
Dessa forma é possível analisar que um dos motivos que justificariam a intencionalidade de obtenção de diagnósticos seria a comprovação da necessidade de frequência no AEE por aqueles alunos que demonstram um desencaixe entre as aspirações da escola e as possibilidades reais de aprendizagens que são apresentadas: "Todos que são atendidos e possuem adaptações no ensino regular tem diagnóstico clínico, pertencentes ao público alvo" (EE).

Fica claro que para a organização do trabalho da professora de educação especial entrevistada, o diagnóstico é condição para a efetivação do atendimento dos alunos no AEE e para a realização de articulação entre ela e o professor de sala de aula. Há uma verdade que indica a necessidade do diagnóstico que supostamente justificaria os comportamentos dos alunos e os localizaria na condição de alunos pertencentes ao público alvo da educação especial.

Nesse contexto alunos são capturados pela necessidade de diagnóstico por não se encaixarem nos padrões de normalidade estabelecidos. As práticas escolares voltadas ao diagnóstico parecem compreender que o aluno só passa a ter sua verdadeira identidade a partir do momento em que recebe seu diagnóstico. Uma vez diagnosticado o aluno pode ocupar legitimamente o lugar de aluno público-alvo da educação especial, tendo assim garantido o seu direito de frequentar o AEE.

Sob orientação das políticas públicas, a partir da efetivação do diagnóstico, o professor de educação especial poderá oficialmente atuar sobre o aluno. A centralidade da prática da educação especial na existência de diagnósticos é produzida pelos próprios documentos legais que amparam a efetivação de práticas inclusivas na escola quando indicam quem são os alunos que podem ser atendidos pela educação especial, beneficiando-se do AEE.

Nesse processo seria possível compreender que há dificuldades e empecilhos nos processos de aprendizagem que não possam ser compreendidos e justificados a partir do saber da área clínica? Entende-se que adaptar conteúdos, orientar professores, realizar práticas articuladas são ações que não são diretamente orientadas por aquilo que o saber clínico pode produzir. Ao discutir a produção da anormalidade no contexto escolar inclusivo indicamos a compreensão de que a necessidade de medicalizar para poder atuar parece ter se estabelecido como uma prática naturalizada na educação especial. Essa aliança entre área médica e saberes pedagógicos, conhecida como responsável pela criação da educação especial, provocou sobre os sujeitos com deficiência representações limitadas e estigmatizantes.

Ocorre que com a emergência das políticas de inclusão escolar essa perspectiva clínico, destinada aos sujeitos com deficiência parece ter se alastrado pelo espaço da escola, tendo hoje como alvo todo e qualquer comportamento que escape ao padrão instituído. Nesse contexto qualquer aluno pode ser alvo da produção diagnóstica se apresentar em algum momento de sua trajetória escolar dificuldades em se adequar diante da norma.

Assim, mediante uma dificuldade de aprendizagem, os encaminhamentos clínicos feitos pela escola podem ser percebidos como elementos de captura dos alunos e também de alívio por parte das famílias e do professor, pois ao produzir-se um diagnóstico produz-se também uma suposta estratégia para a administração das dificuldades no percurso escolar. 
"Quando surge algum aluno com dificuldade na aprendizagem ou de conduta expressiva que necessite de apoio mais específico, fazemos uma observação e percepção e encaminhamos para uma avaliação clínica para comprovar ou descartar quaisquer diagnóstico que possa ser." (EE)

Sob essa compreensão entende-se que as políticas de inclusão podem estar produzindo como efeito um estado permanente de vigilância e controle dos alunos, para que seja possível captar as anormalidades, encaminhando-as a exames que poderão então indicar como melhor conduzi-las novamente à normalidade. Nesse sentido, Camatti (2017) aponta que "prática permanente do exame é, além de comum, necessária. Porém, sua maior pertinência pode estar no outro lado da moeda em que se inscreve: a cada condição diagnosticável, corresponde um encaminhamento. É por eles que regulação se faz mais eficiente" (p. 164).

Com esse tensionamento não procuramos negar a existência de dificuldades nos processos de desenvolvimento e aprendizagem de alguns alunos que podem ser melhor conduzidos a partir da existência de um diagnóstico. O que procura-se fazer é destacar a compreensão de que a escola deve ser um espaço que signifique a aprendizagem como um processo que resulta de estímulos em diferentes aspectos: orgânicos, sociais, afetivos, motores, cognitivos. Ao partir dessa compreensão, parece claro não ser possível que toda e qualquer dificuldade presente nesse processo seja justificada e explicada exclusivamente pelos aspectos passíveis de serem avaliados pela área da saúde:

Ao se debruçar sobre a aprendizagem, a medicina guiará seu olhar pela mesma doutrina apontada por Foucault (1980), no século anterior. Afirmando a existência das doenças do não-aprender (aliadas as doenças do comportamento), colocar-se-á como capacitada a resolvê-las, apregoando a necessidade de disseminação médica pelos ambientes escolares como garantia de aprendizagem adequada, ou, da salvação, ao mesmo tempo, acena para o futuro, com a possibilidade de um tempo em que sua atuação, sua própria existência (da medicina) será dispensável. (Moysés, 2001, p. 182)

Faz-se necessário, então, respeitar a individualidade de cada aluno, atentando para suas peculiaridades e buscando estratégias voltadas àquilo que ele consegue fazer e não ao que ele não consegue ou que acredita-se que ele não vá conseguir. A escola deve ser um lugar de crescimento e desenvolvimento e não de comparações, competições e classificações que resultam em exclusão.

Nesse sentido, é possível analisar, segundo a entrevista, que apesar da condicionalidade do diagnóstico para a organização do trabalho da educação especial na escola, entende-se como importante que se atente para as singularidades que constituem cada aluno nas relações que diariamente são estabelecidas na escola:

"O diagnóstico torna-se importante para compreender o aluno inicialmente, assim como, promover toda e qualquer adaptação necessária que o aluno tem direito. Após, o que conta para apoiar a prática do EE nos atendimentos, são observações e relatos dos professores quanto às dificuldades do aluno diariamente e a troca constante com os profissionais que atendem esse aluno no extracurricular." (EE) 
Quando compreendemos que cada indivíduo é único e aprende conforme sua potencialidade, há significativas possibilidades de a escola passar a não apenas esperar somente os diagnósticos para poder identificar, como também efetivar as práticas em termos pedagógicos, com relação a alguns alunos.

Práticas escolares inclusivas acontecem na medida em que os alunos são avaliados e estimulados conforme suas diferenças e suas diversas formas de aprender. Nesse processo a presença da educação especial pode ser determinante quando opera a produção de transformações nas formas como tradicionalmente compreendem-se as relações entre norma e diferença.

Adaptações, adequações, flexibilizações diante das diferenças individuais são importantes modos de estimular o crescimento nas possibilidades dos alunos e, por isso, entende-se que elas não devam ser operacionalizadas apenas a partir da existência de diagnósticos clínicos, mesmo que sejam importantes em determinadas situações afinal, as singularidades não existem apenas em alguns alunos, naqueles descritos pelas classificações que constituem os manuais médicos:

"O professor passa a adaptar as atividades de acordo com o que o aluno necessita tendo apoio da EE. Assim como, a partir do diagnóstico e orientações quanto a forma de dar aula ou práticas cotidianas precisam ter um olhar cuidadoso para que o aluno esteja incluído e participativo a sua maneira. Como por exemplo, um aluno que só consegue ler e escrever em letra bastão. Um aluno que consegue demonstrar que aprendeu através da oralidade, potencializamos mais sua participação do que o próprio registro." (EE)

No espaço escolar a desconstrução de padrões de normalidade pode acontecer quando se possibilita que os sujeitos possam refletir sobre como tais padrões e perfis ideais de alunos foram sendo produzidos. Assim a escola pode se constituir como espaço de reflexão, que cria possibilidades para a produção e construção de conhecimentos a partir de diferentes modos de aprendizagem que os alunos apresentam.

Segundo Camatti (2017) o ato de diagnosticar surge a partir da Medicina. Inicialmente é este campo do saber responsável pelo conceito e pela prática diagnóstica. Moysés (2001), a partir dos estudos de Michel Foucault, percorre os caminhos da Medicina que a instituem como ciência, demonstrando como seus domínios científicos invadem e estendem-se para outras áreas do conhecimento. A Medicina tem o papel de medicalizar, de dar remédio e oferecer o laudo, mas as outras áreas como a educação podem contribuir para essa avaliação, pois é na escola que o sujeito vivencia os processos sociais, de desenvolvimento e que possivelmente possam vir a influenciar em seus comportamentos e produzir possíveis estigmas.

Assim, parece possível o exercício de suspeita e contestação de certos diagnósticos por parte da escola e da professora de educação especial, afinal, em qual outro espaço se tem tanto acesso a subjetividade da criança? Onde ela passa, por cinco dias na semana, tantas horas do seu dia, em interação com outros sujeitos?

Segundo Moyses (2001) é possível perceber o aumento crescente do processo de medicalização da infância devido a avaliações clínicas mais imprecisas e também às práticas escolares cada vez mais desestimulantes, o que pode vir a ocasionar o desinteresse do sujeito pela aprendizagem de conteúdos formais. Esse crescente no 
processo de medicalização pode tornar a prática educacional um importante artifício de regulação, principalmente da atuação da professora de educação especial, pois na escola põe-se a responsabilidade desses alunos e desses encaminhamentos diretamente nas práticas da educação especial:

"No ambiente escolar houve um crescente na medicalização de crianças, principalmente quanto a concentração e atenção no período de aula. Por vezes se aplica a prática escolar, no sentido da didática, pois está cada vez mais difícil despertar o interesse das crianças que vem de um mundo tecnológico, online e de ter tudo ao seu alcance muito potente." (EE)

Considerando a necessidade de se constituir trocas que estabeleçam qualidade nas relações entre os sujeitos, talvez seja possível considerar que o ambiente da escola comum possa se tornar inclusivo no momento em que se potencializam as relações entre sujeitos diferentes. Diferença entendida como potencialidade e não como falta.

Apostar em escolas inclusivas significa apostar em escolas que proporcionem 0 desenvolvimento dos alunos em seus aspectos afetivos, cognitivos e sociais. Ao olharmos para a escola a partir desses princípios, passamos a compreender o professor como um mediador que, ao se relacionar com o aluno em processo de inclusão escolar, leva em consideração as características pessoais, as formas específicas de aprendizagem que apresentam sua história de vida, cultural e intelectual:

Nessa concepção, as histórias de vida de cada um são compreendidas como elementos necessários para a construção de planejamentos individualizados, propostos a partir dos apoios identificados como necessários para que esses alunos passem a interagir de forma independente, ou com o mínimo de apoio possível, na sociedade. Assim, para possibilitar a aprendizagem e o desenvolvimento do aluno, faz-se necessário deixar de lado os diagnósticos pré-estabelecidos e passar a pensar, então, no sujeito e nas relações estabelecidas ao longo da vida. (Menezes; Castro; Dickel, 2019, p. 17)

Segundo Moysés (2001) a educação se constitui como a melhor possibilidade que milhões de crianças possuem de superar a condição de vulnerabilidade em que vivem, devido à carência de elementos básicos em sua vida como moradia digna, alimentação suficiente, condições de lazer e escolarização atenta às suas singularidades. Tais carências podem estar produzindo muitos problemas de aprendizagem apresentados pelos alunos que não serão superados pela prática de medicalização.

\section{Considerações finais}

Ao procurar compreender possíveis implicações do diagnóstico nas práticas de educação especial a partir dos discursos de medicalização, passamos a perceber como é importante discutir, enquanto professores de educação especial, o lugar de onde percebemos os sujeitos com deficiência. As concepções que embasam a forma como percebemos os alunos, que por sua vez são produzidas a partir de discursos existentes sobre eles, parecem continuar amparadas nos princípios clínicos da área da saúde. 
Encaminhar os alunos para avaliações clínicas em busca de diagnósticos que justifiquem formas de ser parece ser uma prática naturalizada no contexto escolar. Encaminha-se porque entende-se que isso se faz necessário para nossa atuação como professor de educador especial, especialmente quando nos embasamos nos princípios legais que hoje orientam as ações inclusivas e porque, de certa forma, o diagnóstico nos ajuda em nossa prática.

Podemos pensar que devido à forma como as políticas de inclusão estão estabelecidas, as escolas assumem o discurso que naturaliza a necessidade do diagnóstico e convence cada vez mais as famílias a procurarem um caminho que asseguraria mais atenção às especificidades educacionais de seus filhos.

Apesar dos efeitos estigmatizantes que os diagnósticos podem produzir aos alunos, temos nos convencido que ele representaria a melhor saída para a atenção às necessidades de alguns alunos. Nesse sentido perguntamos: o que tem a clínica a dizer sobre as práticas escolares? Como ela pode orientar o que é preciso ser feito na escola em termos de aprendizagem? Como o saber do médico tem contribuído para que toda criança consiga frequentar a escola comum, sendo respeitada em sua singular forma de aprender?

Assim, compreende-se que temos cada vez mais cedo procurado encontrar sinais de anormalidade que algumas crianças possam apresentar para que, também cada vez mais cedo, possam ser corrigidas. Nessa busca nunca foram tão visíveis as estratégias de medicalização da infância produzidas na escola.

Percebe-se que diagnosticar significa dar nome a diferença, o que por sua vez põe o aluno em um lugar muito específico: o lugar de aluno em processo de inclusão que pode e deve ser acompanhado pela educação especial. A diferença quando traduzida em diagnósticos legitima a atuação de ações inclusivas na escola, o que pode tornar a prática voltada à deficiência e trazer benefícios para os alunos, como também pode ocorrer o contrário.

Entende-se que os discursos da medicalização, que têm se constituído como mecanismo de governamento na sociedade contemporânea, produzem a individualização de problemas que são coletivos e assim, adoecendo comportamentos cujas causas são muitas vezes sociais e não orgânicas. Precisamos pensar sobre a captura da diferença via medicalização e em seus efeitos na produção dos alunos, em seus processos de aprendizagem e na conquista de um lugar de inclusão ou exclusão na escola.

\section{Referências}

BRASIL. Política nacional de educação especial na perspectiva da educação inclusiva. Disponível em www.mec.gov.br/secadi. Acesso em 19 out. 2019.

BRZOZOWSKI, Fabíola Stolf; CAPONI, Sandra Noemi Cucurullo. Medicalização dos desvios de comportamento na infância: aspectos positivos e negativos. Psicologia: Ciência e Profissão, Brasília, v. 33, n. 1, 2013, p. 208-221.

CAMATTI, Liane. Efeitos do diagnóstico precoce da surdez nos processos de escolarização de alunos surdos. Santa Maria: UFSM, 2017. 188f. Tese (doutorado em Educação). Universidade Federal de Santa Maria. 
CANGUILHEM, Georges. O normal e o patológico. Rio de Janeiro: Forense Universitária, 2009.

FOCAULT, Michel. A ordem do discurso. São Paulo: Loyola, 1996.

FOCAULT, Michel. Os anormais: curso no Cóllege de France (1974-1975). São Paulo: Martins Fontes, 2002.

FOCAULT, Michel. Vigiar e punir. Petrópolis: Vozes, 1999.

LOBO, Lilian. O nascimento da criança anormal e a expansão da psiquiatria no Brasil. In: RESENDE, Haroldo. Michel Foucault. O governo da infância. Belo Horizonte: Autêntica, 2015, p. 199-215.

LOCKMANN, Kamila. A educação do social e as implicações na escola contemporânea. Educação Unisinos, São Leopoldo, v. 20, n. 1, 2016, p. 58-67.

LOCKMANN, Kamila. As práticas de inclusão por circulação: formas de governar a população no espaço aberto. Cadernos de Educação, Pelotas, v. 19, n. 55, 2016, p. 1936.

LOPES, Maura Corcini. Políticas de inclusão e governamentabilidade. Educação \& Realidade, Porto Alegre, v. 34, n. 2, 2009, p. 153-170.

MENEZES, Eliana da Costa Pereira, ALLES, Elisiane Perufo, CASTRO, Sabrina Fernandes; DICKEL, Cláudia Adriane Graeff. Re-significações no processo de avaliação do sujeito jovem e adulto com deficiência intelectual. Revista Brasileira de Educação Especial, Bauru, v. 25, n. 3, 2019, p. 373-388.

MINAYO, Maria Cecília de Souza (org.). Pesquisa social: teoria, método e criatividade. Petrópolis: Vozes, 2004.

Gabriela Orengo Pedrozo é professora de Educação Especial na rede municipal de ensino de São Pedro do Sul/RS.

Orcid: https://orcid.org/0000-0001-7046-0748.

Endereço: Rua dos Salsos, 135 - 97070-770 - Santa Maria - RS - Brasil.

E-mail: gabpedropedrozo@gmail.com.

Eliana da Costa Pereira de Menezes é professora no Programa de Pós-Graduação em Educação da Universidade Federal de Santa Maria.

Orcid: http://orcid.org/0000-0002-5908-0039.

Endereço: Rua General Neto, 843/301 - 97050-241 - Santa Maria - RS - Brasil.

E-mail: elianacpm@hotmail.com.

Recebido em 26 de setembro de 2019.

Aceito em 11 de março de 2020.

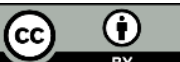

